is not confined to the inoculation spot, but spreads to
the neigh boring parts until it attains a diameter of rom 0.05 to $1 \mathrm{~cm}$.

In a few days it becowes more and more manifest
that the skin thus changed is necrotic finally off, leaving a flat ulceration which usually heals rapid y and permanently without any in volvement of the ad jacent lymphatic glands. Thus the injected tubercular effect is not exclusively produced with living tubercular bacilli, but is also observed with the dead bacilli, the
result being the same whether, as I discovered by experiments at the outset, the bacilli are liilled by a somewhat prolonged application of a low temperature or boiling heat or by weans of certain chemicals. This
peculiar fact I followed up in all directions, and this
further result was obtained-that killed pure cultiva. tions of tubercular bacilli, after rinsing in water might be injected in great quartities under healthy
guinea pig's skin without anything occurring beyond plest and surest means of producing suppurations free from living bacteria.

Tuberculous guinea pigs, on the other hand, are kill-
ed by the injection of very small quantities of such diluted cultivations. In fact, within six to forty-eigh which is not sufficient to produce the dese, an injection wal may cause extended necrosis to the skin in the vicinity of the place of injection. If the dilution is still fur-
ther diluted until it is scarcely visibly clouded, the animals inoculated remain alive and a noticeable improve-
ment in their condition soon supervenes. If the injections are continued at intervals of from one to two days,
the ulcerating inoculation wound becomes smaller and finally scars over, which otherwise it never does; the body beeomes better nourished, and the morbid cess ceases, unless it has gone too far, in which case the
animal perishes from exhaustion. By this means the basis of a curative process against tuberculosis was e Against the practical application of such dilutions
of dead tubercle bacilli there presented itself the fact that the tubercle bacilli are not absorbed at the inoculation points, nor do they disappear in another way,
but for a lung time remain unchanged, and engender greater or sinaller suppurative foci. Anything, ther culous process must be a soluble substance which would be liberated to a certain extent by the fluids of
the body floating around the tubercle bacilli, and be transferred in a fairly rapid manner to the juices of the body; while the substance producing suppuration or dissolves but very slowly. The only important point was, therefore, to induce outside the body the This demanded time and toil, until I finally succeeded, with the aid of a forty to fifty per cent. solution of
glycerine, in obtaining an effective substance from the tubercular bacilli. With the fluid so obtained I made
further experiments on animals, and finally on human further experiments on animals, and finally on human
beings. These fluids were given to other physicians to The remedy which is used in the new

sists of a glycerine is used ne new treatment contivation of tubercle bacilli. Into the simple extract
there natu rally passes from the tubercular bacilli, besides the eff ective substance, all the other matter soluble in fifty per cent. glycerine.

Consequently, it contains a certain quantity of mine-
ral salts, coloring substances, and other ral salts, coloring substances, and other unknown
extractive matters. Some of these substances can be extractive matters. Some of these substances can be
removed from it tolerably easily. The effective sub-
stance is insoluble in absolute alcohol. It can be pre. cipitated by it, though not, indeed, in a pure condi-
tion, but stil combined with the other extractive matter. It is likewise insoluble in alcohol. The
coloring matter may also be removed, rendering it
possible to obtain from the extract a colorless possible to obtain from the extract a colorless, dry substance containing the effective principle in a much
more concentrated form than the original glycerine
solution. For application in practice this purification of the glycerine extract offers no advantage, because
the substances so eliminated are unessential for the the substances so eliminated are unessential for the human organisin. The process of purification
make the cost of the remedy unnecessarily high.
Regarding the constitution of the more effet Regarding the constitution of the more effective
substances, only surmises may for the present be substances, only surmises may for the present be ex-
pressed. It appears to me to be derivative from albu-
minous bodies, having a close affinity to them. It does not belong to the group of so-called toxalbumins, be cause it bears high temperatures, and in the dialyzer goes easily and quickly through the membrane. The
proportion of the substance in the extract to all approportion of the substance in the extract to all ap-
pearance is very small. It is estimated at fractions of one per cent., which, if correct, we should have to do with a matter whose effects upon organisms attacked of the strongest drug.

Regarding the manner in which the specific action
of the remedy on tuberculous tissue is to be riop of the remedy on tuberculous tissue is to be represent
ed, various hypotheses may naturally be put forward. ed, various hypotheses may naturally be put forward
Without wishing to affirm that my view affords the
best explanation, I represent the process inyself in the following manner :
The tubercle bacilli produced when growing in living tissues, the same as in artificial cultivations, contain substances which variously and notably unfavorably
influence living elements in their vicinity. Among centration kills or so alters living protoplasm that it passes into a condition that Weigert describes as coa-
gulation necrosis. In tissue thus become necrotic the bacillus finds such unfavorable conditions of nourish ment that it can grow no more and sometimes dies.
This explains the remarkable phenomenon that in This explains the remarkable phenomenon that in
organs newly attacked with tuberculosis, for instance ed with gray nodules, numbers of bacilli are found,
whereas they are rare or wholly gbsent when the enorwhereas enlarged spleen consists almost entirely of
whitish substance in a condition of coagulation necrosis, such as is often found in cases of natural death in
tuberculous guinea pigs. The single bacillus cannot,
therefore, induce necrosis at a great distance, for a of the bacillus subsides, and therewith the production
of the nerotizing substance. A kind of reciprocal
compensation thus occurs, causing the vegetation of isolated bacilli to rewain so extraordinarily restricted,
as, for instance, in lupus and scrofulous glands. , for instance, in lupus and scrofulous glands.
In such cases the necrosis generally extends only to assume the peculiar form of riesen zelle, or giant cells. If now one increased artificially in the vicinity of the
ion acillus the amount of necrotizing substance in the The conditions of nourishment for the bacillus would thereby become more unfavorable than usual. In the first place the tissue which had become necroand where such were possible would carry off the in-
closed bacilli and eject them outwardly, so far disturbing their vegetation that they would much more speed It is just in looking at such changes that the effect of the remedy appears to consist. It contains a certain large dose of which injures certain tissue elements even puscles or adjacent cells, thereby producing fever and patients a wuch smaller quantity suffices to induce a ating and have already impregnated the adjacent region with the same necrotizing matter, more or less ex the whole organisin which result from and are connect For the present, at least, it is impossible to explain the specific influence which the rewedy, in accurately
defined doses, exercises upon tuberculous tissue, and the posibility of increasing the doses with such re-
markable rapidity, and the remedial effects which have unquestionably be
vorable circuinstances.

Or the consumptive patients whom he described a Moabit Hospital for further observation.
Moturned to the No bacilli have appeared in their sputum for the past three months, and their phthisical
gradually and completely disappeared.

\section{CAN WE SEPARATE ANIMALS FROM} PLANTS ?

By ANDREW WILSON.

ONE of the plainest points connected with the study of living things is the power we apparently possess of
separating animals from plants. So self-evident apdea of science modestly disclaiming its ability to sepahere any danger of confusing a bird with the tree
there amid the foliage of which it builds its nest, or of misof course, answerable in one way only. Unfortunately
(for the querists), however, they do not include or comprehend the whole difficulty. They merely assert,
what is perfectly true, that we are able, without trouble, to mark off the higher animals from the higher
plants. What science inquires is. whether we are able to separate all animals from all plants, and to fix a
definite boundary line, so as to say that all the organisms on the one side of the line are assuredly animals,
while all the others on the opposite side of the line task which science declares to be among the impossibilities of knowledge. A A way down in the depths of ty of living things becomes of a nature which is worse
than confusing, and which renders it a futile task to attempt to separate the two worlds of life. The hopeso forcibly that they have proposed to constitute a third kingdom-the Regnum Protisticum-between the host of doubtful organisms. This third kingdoun
would resemble the casual ward of a workhouse, in would resemble the casual ward of a workhouse, in
that it would receive the waifs and strays of life which could not find a refuge any where else.
A very elight incursion into biological felds may the task of separating animals from plants is wooted for discussion. To begin with, if we suppose our popu-
lar disbeliever to assert that animals and plants are always to be distinguished by shape and form, it is easy enough to show him that here, as elsewhere, ap
pearances are deceptive. What are we to say of a sponge, or a sea anemone, of corals, of zoophy tes grow-
ing rooted from oyster shells, of sea squirts, and of sea mats? These, each and all of them, are true animals, but they are so plant-like that, as a matter of fact,
they are often mistaken by seaside visitors for plants.
This last remark holds especially true of the zoophytes and the sea mats. Then, on the other hand, we can point to hundreds of lower plants, from the yeast
plant onward, which show none of the ordinary features of plant life at all. They posess neither roots, first count of the indictment the naturalist gains the Pay. is certain to appeal, is an equally baseless ground of
separation. For all the animals I have above named grade are never rooted at all. The yeast plant, the Alga that swarm in our ponds, and the diatoms that
crowd the waters, exemplify plants that are as free as
animals; and many of them, besides, in their young animals; and many of them, besides, in their young
state especially (e.g., the seaweeds), swiw about freely the second count, also, science gains the day ; power ing one living being as an animal, while absence of movement is similarly no reason for assuming that the moved organism must of necessity be a plant. Then
cowes tine microscopic evidence. What can this wonder glass do in the way of drawing boundary lines be
twixt the living worlds? The reply again is disapus that the tissues of animals and plants are built upon the other tokens of its beauty and its life. f the debris of the animal frame the green plant

kindred lines. We meet with cells and fibers in both.
The cell is in each case the primitive expression of the whole organisin. Beyond cells and fibers we see the
wonderful living substance, protoplasm, which is alike ork. On purely microscopic grounds, we cannot tion for rigidly assuming that this is a plant or that an animal on account of anything the microscope can
disclose. A still wore infortant point in connection with this protoplasiu question consists in the fact that nearer to an identity of substance which baffles the speck of this living jelly. The germ of each is a pro-
toplasm particle, which, whatever traces of structure it way exhibit, is practically unrecognizable as being Later on, as we know, the egr or germ shows traces plants; while even lowly forms of life exhibit wore or
less characteristic phases when they reach their adult Btage. But, of life's beginnings, the microscope is as
utile as a kind scientific touchist one for distinguishing A fourth point of appeal in the matter is found with in the domain of the chemist. Chemistry, with its subtile powers of analysis, with its many-sided possiwith its ability to analyze for us even the light of the far distant stars, only complicates the difficulties of the
biologist. For, while of old it was assumed that a par. hat carbon was an element peculiar to plants, we now moreover, when it did grow to become a staple part of science, revealed other and greater anomalies than
these. It showed that certain substances which were upposed to be peculiar to plants, and to be made and mals. Chlorophyl is fthe green coloring watter of plants, and is, of course, a typical product of the vege
table world ; yet it is made by such animals as the hy dra of the brooks and ponds, and by many animalcules and some worms. Starch is surely a typical plant proof unan himself, which occasionally produces sugar out Again, there is a substance called cellulose, found well Again, there is a substance called cellubse, found we
pigh universally in plants. Of this substance, which is
akin to starch, the walls or envelopes of the cells of plant tissues are composed. Yet we find those curious animals, the seasquirts, found on rocks and stones a
ow-water mark, manufacturing cellulose to form part nd parcel of the outer covering of their sac-like manufacturer, had infringed the patent rights of the composition-the verdict is that nothing that chemistry can teach us may serve definitely, clearly, and exactly
to set a boundary line or to erect a partition wall beween the two worlds of life. There yet remains for us consider a fifth head-that of the food.

In the matter of the feeding of the two great living gounds for making up the one kingdom from the other. What the consideration of form, movement, chem-
ical composition, and wicroscopic structure could not estigation of the diet of animals and plants would ren. der clear. Our hopes of distinguishing the one group
from the other by reference to the food on which ani-
mals and plants subsist are, however, dashed to the yround; and the diet question leaves us, therefore. Nevertheless, it is an interesting story, this of the scientific information is to begleaned from such a study. which may very well be commenced by our having reemphasize the word "green," because it so happens that when a plant has no chlorophyl (as green color is
named in the plant world) its feeding is of diverse kind to that which a green plant exhibits. The mushroom or other fungus may be taken as an illustration of a common plant, from a bit of grass to an oak tree, ex
emplifies the green-bearing order of the vegetable Suppose we were to invite a green plant to dinner, from that which would satisfy a human or other ani-
fould mal guest. The soup would be represented for the oint by carbonic acid gas, and the dessert by ammo-
ia. On these four itews a green plant feeds, out of them it builds up its living frawe. Note that its diet is of inorganic or non-living watter. It derives its susters the green plant elaborates and manufactures its organism than the animal, for while the latter can only in its food supply, the green plant, by the exercise of its vital chemistry, can transform that which is not
living into that which is life-possessing. living matter, while the animal can only transform living watters into its like. This is why the plant is called a constructive organism, while the animal is, the plant's existence is to build up, that of the animal's
life is to break down its substance, as the result of its work, into non-living watter. The animal's body is, in green plant feeds. We ourselves are perpetually disthe carbonic acid, water, ammonia, and ininerals on as that in which the apostle used the term. And out to our senses in the two kingdons, although, indeed,
differing much here and there in the results of its aing and plants, we seem to approach nearer and animal and every plant begins existence as a mer that carbon was an element peculiar to plants, we now
know that both elements are found in animals, just as
both occur in plants. The chemistry of living things, hen it has been discussed, in the same quandary a. 


\begin{abstract}
If, then, an animal can only live upon living matter
-that is to say on the bodies of other animals or of plants - with water, minerals and oxygen gas from the air thrown in to boot, we might be tempted to hold
that in such distinctive ways and works we had at Unt found a means of separating animals from plants. and rendered null and void, on two grounds. First of all true plants, do not feed as do the green tribes. And secondly, many of the greeu plants themselves can be
of diet. A mushroom, thus, because it has no green color
lives upon water, oxygen, minerals, and organic ter. You can only grow mushrooms where there is plenty of animal watter in a state of decay, and as for were animals. Non-green plants thus want a most characteristic action of their green neighbors. For the is composed of carbon and oxygen. Under the com
bined influence of the green color and the light, they split up the gas into its two elements, retaining the the atmosphere. Alas! however, in the dark our green plant becomes essentially like an animal as re-
gards its gas food, for then it is an absorber of oxygen, while it gives off carbonic acid. If to take in carbonic characteristic of a plant, it is one, as has been well said, which disappears with the daylight in green have no green color.

So far, we have seen that not even the fond of plant and animals can separate the one kingdom of life from
the other. The in ushroom bars the way and the green plant's curious behavior by night and by day respectvely, in the watter of its gas food, once more assimilates animal life and plant life in a remarkable man-
ner. Still more interesting is the fact, already noticed
that even among the green tribes there are to be found that even among the green tribes there are to be found feeding. Thus what are we to say of the parasitic mis can, therefore, obtain so much carbon food from the air on its own account, nevertheless drinks up the sap.
of the oak or apple which forms its host, and thus illustrates the spectacle of a green plant feeding like an
animal, on living matter? Or, what may we think of animal, on living matter? Or, what may we think of
such plants as the sundew, the Venus' fly trap, the such plants as the sundew, the Venus' fly trap, the
pitcher plants, the side saddle plants, the butterworts and bladderworts, and others of their kind, which plex lures, but also .digest the animal food thus cap-
tured? A sundew thus spreads out its lure in the shape of its leaf studded with sensitive tentacles, each capped by a glistening drop of gumwy serretion. Entangled in this secretion, the fly is further fixed to the
leat by the tentacles which bend over it and inclose it body a digestive acid fluid, and the substance of the dissolved and digested animal is duly absorbed by the
plant. So also the Venus' fly trap captures insects by plant. So also the Venus' fly trap captures insects by
means of its leaf, which closes upon the prey when certain sensitive hairs have given the signal that the ani-
mal has been trapped. Within the leaf the insect is wal has been trapped. Within the leaf the insect is
duly digested as before, and its substance applied to the nutrition of the plant. Such plants, moreover, cannot flourish perfectly unless duly supplied with their animal food. Such illustrations of exceptions to the rule of green plant feeding simply have the effect of
abolishing the distinctions which the diet question We may return to the sundews and other insect catchers; meanwhile, I have sai 1 enough to show that to the question, "Can we separate animals from plants?" a very decided negative reply mast be given. Life
everywhere exhibits too many points of contact to ad. mit of any boundary line being drawn between the
i wo great groups which make up the sum total of I wo great groups which make up the sum
organic existence.-Illustrated london News.
\end{abstract}

THE RECOVERY OF SILVER AND GOLD FROM PLATING AND GILDING SOLUTIONS

IN view of the rapid development and extension of the methods of electro-plating with silver and gold, and or gold thus produced, it has long been desirable to find methods by which these metals can be recovered
from the spent liquors. The processes hitherto adopted generally necessitate the tedious and unpleasant evap of chemical operations which are somewhat difficult to carry out, so that actually the used-up baths are sold to some firm which undertakes this recovery as a
particular branch of its business. A process invented by Stockinuir and Fleischmann and worked out by them in the chemical laboratory of ingly simple, and is employer in many establishments. In order to remove silver from a potassium cyanide
silver solution, it is only necessary to allow a clean piece of plate zinc to remain in the liquid for two days ;
even better results are obtained by the use of iron coneven better results are obtained by the use of iron con-
jointly with the zinc. In the first case, the silver of ten jointly with the zinc. In the first case, the silver often
adheres firmly to the zinc, while in the second it always separates out as a powder. It is then only necessary to
wash the precipitated powder, which usually contain copper (since spent silver solutions always contain copper). dry it, and then dissolve it in hot concentrated
sulphuric acid, water being added, and the dissolved silver precipitated by strips of copper. The silver
thus obtained is perfectly pure. If the amount of copthus obtained is perfectly pure. If the amount of cop-
per present is only small, it can usually be removed by fusing the precipitated powder with a little niter and
borax. In this way
tain per liter

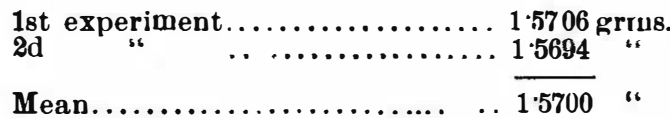

The preance of silver could not be qualitatively as certained in the residual liquor.
Although sheet zinc, or zinc and iron sheets, serve Bo well for the precipitation of silver, they cannot be

\section{employed for the recovery of gold. The latter sepa- and, finely divided zinc, the so-called zinc dust, is a quantitatively and in the form of powder from spent gold bath and the liquid periodically stirred or shaken amount of zine to be added naturally depends on the quantity of gold present. Freshly prepared gold baths for gilding in the cold contain ons the average 3.5 grms tain $10^{\circ} 75$ grms. To precipitate all the gold in the orig-
inal bath, 1.74 grms. or $0.37-0^{\circ} 5$ grins. zinc dust would be necessary, and, of course, a much smallerquantity would be sufficient for the spent liquors. Since the precipitation takes place more rapidly when au excess
of zinc dust is present, it is generally advisable to add $1 / 4$ or at the most $1 / 2$ kilo. of zine dust to every 100 liter The precipitated gold, which contains zine dust and by hydrochloric acid, and then from silver and copper by nitric acid and thus obtained pure. \\ A spent bath treated in this way gave the following 1st experiment. \\ $0 \cdot 2626$
$0 \cdot 2634$ Mean. 0.2630 grms. \\ The presence of gold in the residual cyanide solution cyanide of the solutions obtained by this process should be converted into ferrocyanide by heating with ferrous poisonous and can therefore be got rid of withou
danger. It would, however, be more economical and considering the large amount of cyanide present, more
profitable to work it up into Prussian blue. \\ a New Catalogue of Valaable Papers \\ Contained in Scientific American Supplement during the past ten years, sent free of eharge to any
address. MUNN \& CO., 361 Broadway, New York. \\ THE SCIENTIFIC AMERICAN Architects and Builders Edition.}

\section{$\$ 2.50$ a Year. Single Copies, 25 cts.}

This is a Special Edition of the ScIentific AMERIAach number contains about forty large quarto pages, equal to about two hundred ordinary book pages,
forming, practically, a large and splendid Magazine of Architecture, richly adorned with elegant plates most interesting examples of modern Architectura nstruction and allied subjects.

A special feature is the presentation in each number a variety of the latest and best plans for privat noderate cost as well as the more expensive. Draw ith full Plans, Specifications, Costs, Bills of Estimate. No other building paper contains so many plans,
sols details, and specifications regularly presented as th lready been erected on the various plans we have process of construction. Architects, Builders, and Owners will find this work aluable in furnishing fresh and useful suggestions erecting structures of any kind, have before them in cainples from which to make selections, thus savin Many other subjects, including Sewerage, Piping uighting, Warming, Ventilating, Decorating, Laying Compendium of Manufacturers' Announcements is also given, in which the wost reliable and approved Build re described and illustrated, with addresses of th makers. etc.
The fullness, richness, cheapness, and convenience of
this work have won for it the Largest Circulation any Architectural publication in the world

A Catalogue of valuable books on Architecture Building, Carpentry, Masonry, Heating, Warming pertaining to the art of Building, is supplied free of harge, sent to any adiress.

\section{MUNn \& Co., Publishers} 361 Broadway, New York.

\section{Building Plans and Specifications.}

In connection with the publication of the BuILDING
EDITION of the ScIFNTIFIC AMERICAN, Messrs. Munn \& Co. furnish plans and specifications for buildings
of every kind, including Churches, Schools, Stores, wellings, Carriage Houses, Barns. etc.

In this work they are assisted by able and experitions fcr the various buildings illustrated in this paper can be supplied.
Those who contemplate building, or who wish to alter. improve, extend, or add to existing buildings, whether wings, porches, bay windows, or attic rooms,
are invited to communicate with the uudersigned. Our work extends to all parts of the country. Estimates, plans, and drawings promptly prepared. Term MUNN \& CO., 361 BROADWAY, NeW YORK.
$\boldsymbol{T} \mathbf{T}$

Scientific American Supplement.

PUBLISHED WEEKLY.

Terms of Subscription, $\$ 5$ a year.

Sent by mail, postage prepaid, to subseribers in any
part of the United States or Canada. Sis dollars a part of the United States or Canada. Sis dollars a
year, sent, prepaid, to any foreign country. A All the back volumes of THe SUPPLEMENT can like wise be supplied. Two volumes are issued yearly.
Price of each volume, $\$ 2.50$ stitched in paper, or $\$ 3.50$ COMBINED RATES.-One copy of ScIENTIFIc AMERICAN and one copy of ScIENTIFIC AMERICAN SUPPLEMENT, one year, postpaid, $\$ 7.00$.
A liberal discount to booksellers, news agents, and

MUNn \& CO., Publishers,

361 Broadway, Now York, N. Y.

TABLE OF CUNTENTB.

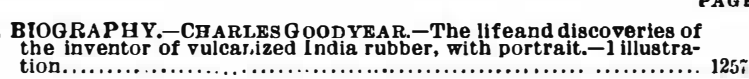

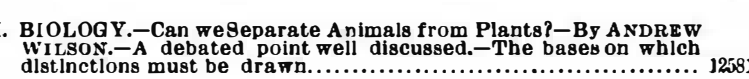

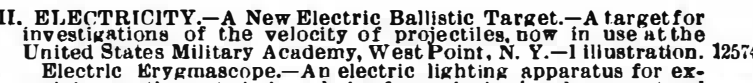

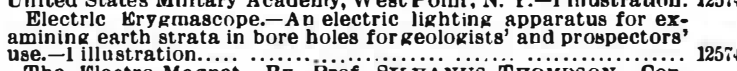

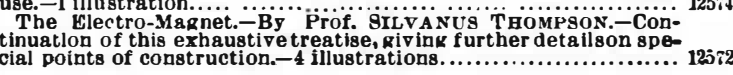
EN TOMOLOOY.-Potash Salts.-The useof potash saits as insec-
tlcides, with accounts of experiments.............................. 125\%

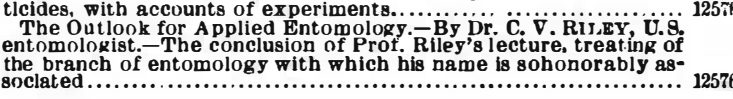

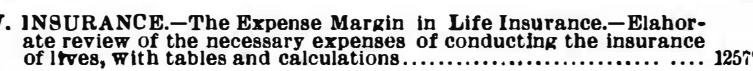

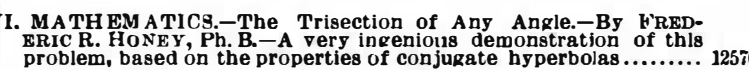

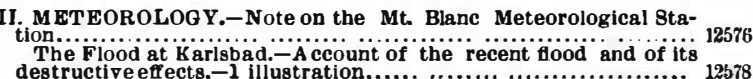
VIII. MECH ANICAL ENOINEERING.-Station for Testing Agri-
cuiturai Machines.-A proposed estabiishment for appiying d9:

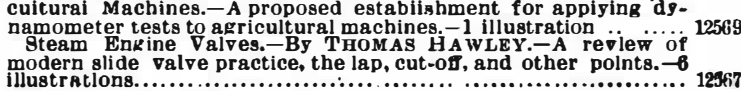
X. MISCELL, ANEOUS.-Science in the Theater.-Curious examples
of stake effect in fletitious mesmer ring and hypotizing. 4 illus-

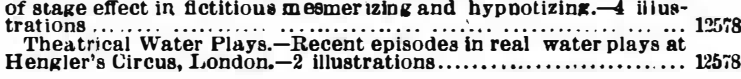

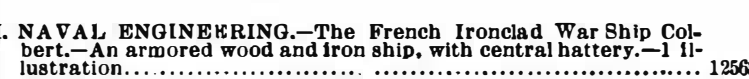

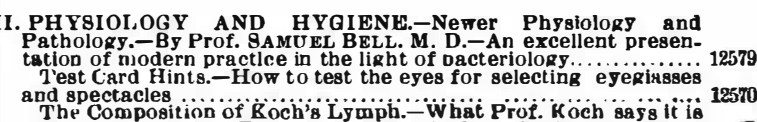

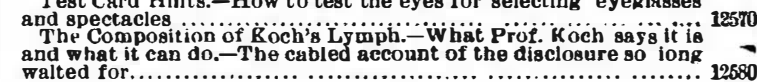
II. TECHNOLOGY,-Wiring Points of Varlous Explosives. - The
ieadine explosives, with the temperature of their exploding points
tabulated

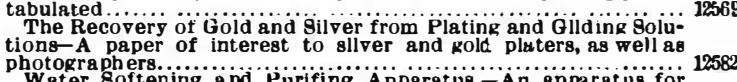

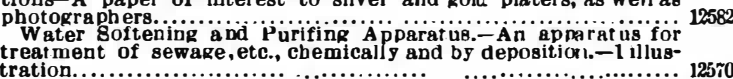

\section{Useful Engineering Books}

\section{Manufacturers. Agriculturists, Chemists, Engineers,} Mechanics, Builders, men of leisure, and professional the transmission of books through the mails at very small cost. A comprehensive catalogue of useful book the office of this paper. Subjects classitied with names of author. Persons desiring a copy have onl

MUNN \& CO., 361 Broadway, New York.

\section{PATENTS.}

In connection with the Scientific American,
Messrs. MUNN \& Co. are solicitors of American and oreign Patents, have had 42 years' experience, and ow have the largest establishment in the world A special notice is made in the Scientific Ameriwith the name and residence of the Patentee. By the mmense circulation thus given, public attention jo
directed to the merits of the new patent, and sales or directed to the merits of the new patent, and sales or Antroduction of ten easily effected.
Any person who has made a new discovery or invenAny person who hastain. free of charge, whether a patent Wealso send free our Hand Book about the Patent
Laws, Patents, Caveats. Trade Marks, their costs and how procured. Address

MUUIJI de 00. 361 Isroadwar, New York.

Branch Ofice, 622 and 624 F st., Washington, D. C. 